\title{
Tourism in the rust belt: using the past as an economic development strategy
}

\author{
J. Eyles \\ Institute of Environment and Health, McMaster University, Canada
}

\begin{abstract}
Tourism is seen as a major strategy for urban renewal in many cities in North America, particularly in those places in which there has been significant industrial downsizing. Changing leisure patterns in such cities have exacerbated the problem of the downtown core. Not only have many aspects of the culture of consumption fled the downtown but also so have many office and warehousing functions. Faced with these problems - but with an outgoing commitment for the viability and sustainability of the core - many cities have made significant investments in landscaping, policing and financial instruments. However, many of the rust belt cities have not been revived. Using case studies from the American mid-west and southern Ontario, the possibilities of sustainable urban futures through tourist investments will be assessed. The asset base as well as the financial and political climate will be seen as key. It may be concluded that except for a few places, sustainable success will be illusory.
\end{abstract}

Keywords: deindustrialisation, tourism, sustainability, Hamilton, Canada.

\section{Introduction}

Many manufacturing cities in the eastern part of North America have seen tremendous declines in industrial presence and therefore employment opportunities over the last 25 years or so. For example, Hamilton, renowned as a steel manufacturing centre in Ontario, has seen job numbers in steel decline some 600 percent to just over 4000 people. In fact, since the 1980s, Hamilton has a 'job deficit' with an increasing number of people leaving the city for work with fewer commuting in from other municipalities [1]. Hamilton, like other cities in the so-called rust belt has responded in a variety of ways to try to ensure continued investment, employment opportunities and residential interest. One of 
these responses has been the development and/or enhancement of tourism. Indeed, since 1980, many cities similar to Hamilton have responded in this way not always successfully. For example, Flint, Michigan, experienced significant and highly publicised decline, captured by Michael Moore's film 'Roger and Me', about the impacts of the car closings on the city. Among Flint's responses to deindustrialisation were several schemes to promote tourism, including the creation of a theme park, 'Auto World'. This urban indoor theme park costing about $\$ 80$ million opened in 1984 and closed - bankrupt - in 1986. While different stakeholders emphasise different reasons for this failure - poor planning, no business plan, insufficient vision - Flint's failure points to the problematic nature of tourism as an economic development strategy, especially as a local response to global forces (see [2]). But is it possible for cities like Flint and Hamilton to refashion themselves through tourism? In this paper, tourism as an economic development strategy will be reviewed before the case study of Hamilton is presented. It will examine then both the sustainability of tourism and sustainable tourism before turning to the necessary and sufficient conditions of economic redevelopment success.

\section{Tourism as development}

In an early paper, Roche [3] highlights how recent a phenomenon urban tourism is. He persuasively argues that urban tourism, while a response to employment decline through diversification into service sector industries, is also a dimension of the trend towards post-industrialism and post-nationalism. Thus postindustrialism challenges the assumption of full employment and employmentbased citizen identities. This challenge is reinforced by post-nationalism with the rise of transnational corporations (and increase in footloose capital) and the apparent decline in the ability of the nation-state to protect its citizens and provide them with employment opportunities, choices and identities. Thus in countries like the U.S. and Canada, high technology societies with increased discretionary 'leisure' time may in part respond to these challenges by the growth of service sector jobs including generating a strong tourism market and industry. But such responses may have adverse consequences in that many of the jobs created are low-wage, especially when compared to the manufacturing ones they appear to replace and the opportunities to create a strong tourism market may not be geographically evenly distributed. Can, for example, both Flint and Cleveland succeed? Can Hamilton and Windsor? It is certainly possible for industrial land-use to be modified into a tourist-oriented industrial landscape as Mansfeld's story of Haifa [4] as that of Roberts and Schein of Syracuse [5] suggest. In the case of Haifa, for example, a unique topography, seafronts and urban infrastructure were compromised by the difficulty of retaining hi-tech employment, the difficulty of attracting private investment for hotels and competition from other cities, especially Jerusalem and Tel Aviv

So are there critical factors that will help a locality emerge as a successful tourism space? Rogerson argues that first and foremost a city must develop a total tourism portfolio to attract visitors [6]. This portfolio is a combination of 
resources and services, with their quality and diversity being key for success. The resource or asset base consists of natural, built environment and cultural elements. And while tourism has tended to emphasise shopping and the arts and sporting events, increasing attention is being paid to the natural environments of urban areas. Waterfronts and urban parks are seen as key elements for residents and tourists. Urban nature provides important social and psychological benefits for individuals and contributes to the sustainability of the city itself (see [7]). Emphasising the 'natural' may be seen as a more sustainable form of tourism than one that emphasises attractions and events in that it serves residents as well as visitors. Indeed for any tourist activity to be a success it must provide both a satisfactory experience for visitors and an improvement to the quality of life of local inhabitants (see [8]). Secondly, success of a tourist space depends on 'locality development', i.e. the overall planning and management of physical and economic development in the locality [9]. Such planning and management may involve incentives for investors in terms of tax abatements and developmentfriendly land-use regulation. But it also needs to encompass local resident involvement - participatory planning practices, training and job opportunities. Thirdly, tourist destinations must themselves be managed. For example, there may be competition for the use of resources between tourism and other activities and demands. Natural landscapes - which in themselves require a sustainable strategy - may become despoiled and less attractive if they attract too many visitors. Briassoulis in fact writes of the tragedy of the tourist commons in which through overuse, low investment and poor management of the destination - the tourist portfolio in general - may be degraded [10]. Such degradation can result in a decline in the attractiveness of the tourism asset. So management of resources must deal with decline and growth and the need to introduce new products to sustain the place as a tourist destination. A long-term development strategy is therefore required involving input from the stakeholders (see [6]). In assessing such strategies, it is easy to concur with Davidson and Maitland [8] who conclude that the aims for developing tourism strategies must be clear, must adopt the perspective of the tourist and yet ensure any facilities are as desirable to local people as to tourists to help mitigate any local resentments. These are not easy tasks, especially as tourism must be seen as one of many possible development approaches.

\section{Urban tourism and economic regeneration and development}

Urban tourism must be seen as part of local (and perhaps community) economic development. In fact, its current foci point to it being one element in the socalled 'third wave' of economic development efforts with their emphasis on creating the context for economic growth through public-private partnerships, networks that encourage capital and human resources to increase comparative advantage [11]. Yet most states and cities have similar priorities and activities, i.e. retain and expand existing business, expand tourism, build or rebuild infrastructure and promote high technology, knowledge-intensive industries. 
Through tax incentives, loans, business support centres and the like, existing and new development is retained or attracted. There is debate on whether economic incentives work or rather if their repercussions are all positive. Certainly, Zremski has argued that high taxes, extensive regulation and excessive energy costs in New York State has disadvantaged such cities as Buffalo and Syracuse compared with the smart-growth strategies of Wisconsin and Michigan [12]. Thus industry and business incentives may simply redistribute jobs between cities. Yet tourism may provide locality-specific advantages as the assets are or must be made unique. Thus higher expenditures of economic development dollars go to tourism as opposed to other industries [11].

So is tourism a way forward for economic regeneration? Great potential is recognised, especially when emphasis placed on the high profile cities Baltimore and Boston being the first to use tourism as a regeneration strategy. And tourist investments are often viewed as different from other kinds of development expenditure. As Law points out, tourism investments involve the physical development of facilities and infrastructure which will benefit the local community as well [13]. It also means the marketing or selling of an image - the branding of the city - which may increase civic pride. Many of these facilities may already exist - theatres, galleries, museums, parks and greenspaces, waterfronts, historical/religious buildings and so on. These primary elements require a solid infrastructure - hotels, shops, restaurants, policing, information services - as well as a cultural context (customs, folklore, security) [14]. It may also involve sporting stadia events, festivals and special events but there is little evidence that such activities create sustained or long-term benefit to communities. For example, building sports stadia in U.S. cities has brought local communities few economic benefits, although benefit may be found in the satisfaction or pride in having a local team [15]. Furthermore many tourism jobs are lower paid. In a study of tourism in Wisconsin, it was noted that for 2001-2, while tourism generated over 320,000 jobs, average incomes were less than half those in 'all industries' [16].

Yet urban tourism remains a favoured strategy, with, as suggested, much attention being given to high profile, successful developments. Thus Barcelona and Bilbao are often cited as successful examples of cities that have regenerated themselves through tourism. Bilbao has been used as a model for Hamilton, Ontario and Sheffield [17] and Milwaukee [18] not recognising the importance of context especially political and cultural conditions. Bilbao worked because of Basque civic pride, the Basque region's relation to central government in Spain, and the availability of national and EU resources to increase vastly locally derived investments.

Perhaps few would disagree that elements of 'third-wave' economic development as necessary for tourism, namely the importance of leadership, good governance, the availability of information on what is available and happening and the role of brokering, especially coordinating economic development with other activities, private-public partnership and branding and marketing [11]. Even with such characteristics, successful tourism developments do not necessarily impact in a positive way on entire cities. So in Boston and 
Baltimore, there remain pockets of poverty and dereliction close to high profile developments. Furthermore for success, the context of the development of the tourism portfolio must be recognised as must the scale of tourism activities and their likely benefits in economic regeneration. In this respect, scale refers to the size and location of the resources (e.g. shopping districts as destinations) and the type of user (tourist, excursionist, resident) (see [19]). How has context and scale enhanced our thwarted tourism as development in such rust belt cities as Hamilton?

\section{Tourism as development in Hamilton}

Hamilton provides a good example of an old, industrial city in search of its future. Given its size and economic role, it has more in common with such cities as Flint and Toledo [20] as opposed to Pittsburgh or Toronto, larger places with more diverse business and investment environments. What kind of city is Hamilton? How does it define its future? And what will be the role of tourism in these plans?

Hamilton is a city which is growing slowly - at about half the rate - relative to Ontario as a whole [21]. Furthermore, its reliance on manufacturing remains challenging as further agglomeration, especially in steel, is likely to reduce this sector's share of employment opportunities even further. Hamilton has however long recognised these challenges. A nationally significant industrial city in the nineteenth century, it remains so today despite the comparative decline (in employment terms) of steel and related industries. Hamilton has a highly industrialised core but contains significant rural areas [22] and the service and tertiary sectors continue to grow with respect to employment opportunities. Furthermore, the decline of its manufacturing base resulted in Hamilton undertaking a process that led to its designation as a sustainable community, which emphasised the importance of environmental as well as social and economic dimensions of urban life and development. Hamilton developed a sustainable vision (VISION 2020 - see [22]) that has perhaps been modified over the last 5 years or so with the initiation of GRIDS, the growth related integrated development strategy. The purpose of GRIDS is to identify the most ideal places for growth and the type of growth based on environmental priorities, social issues, economic opportunities and population studies as well as to identify strategies to fund the services of these areas [23]. Within GRIDS, Hamilton has opted for a cluster development strategy, recognising the challenge of competing with other cities for investments and business relocations on the basis of tax incentives. Three clusters are identified: traditional (advanced manufacturing, agriculture and food processing, port-related industries), emerging (aerotropolis (airport-related), biotechnology, and film and culture industries) and non-traditional (tourism and downtown) [24]. These clusters largely build on what already exists in the city and reviews of the city's annual performance in attracting investment suggest like most struggling places, Hamilton will largely accept any investors waiting to expand or relocate and has in fact development major industrial parks to attract business (see [25]). 
Tourism is then seen as a potential cluster for economic development and regeneration. A municipal organisation was created in 2002 - Tourism Hamilton - and has undertaken analysis of tourist assets, product and experience investment and development and training, marketing and promotion. Tourist expenditures are certainly growing, from \$162 million reported in 2005 to $\$ 186$ million in 2008 [24, 26], the latter being a small share of Ontario's touristgenerated income ( $\$ 17$ billion). Furthermore, most visitors to Hamilton are Canadian (92 percent), unlikely to overnight in the city (22 percent do) and are more likely to visit friends and relatives (61 percent). Tourism then is a minor, localised activity, further demonstrated by low level of hotel occupancy (60 percent) and small contribution of tourism to employment (2400) and municipal tax base ( $\$ 4.2$ million) [27].

So is tourism a sustainable strategy for economic regeneration for Hamilton? It may be it can contribute one, albeit minor, dimension. Hamilton suffers from a poorly developed service structure in terms of quality hotels and urban infrastructure in general. Its downtown is in need of refurbishment and consumes much municipal attention and expenditure despite the growth of the city's suburban shopping malls and other attractions. But there are certain positive elements. The city has been reasonably successfully in attracting special events, often sports-related, but its main entertainment facilities do not stage activities on a full-time basis. Entertainment facilities are currently subsidised by municipal taxpayers to the tune of $\$ 2.7$ million per year [28]. Its primary resources are largely small-scale and appeal to different market segments, including the Art Gallery of Hamilton, Theatre Aquarius, the Marine Discovery Centre, Flamborough Casinos and the HMCS Haida. Hamilton remains a green city with waterfront parks, trails (including part of the Bruce Trail), wetlands, the Niagara escarpment and much agricultural land (some 40 percent of its land area is rural). Little has yet been made of these natural assets to make sustainable tourism sustainable. These assets have not yet been made central to any tourism promotion.

\section{Conclusion}

So how important is tourism for Hamilton? And how important can it be for its future? In responding 'not very' to both questions, Hamilton is in a similar position to many deindustrialising cities, although there is the recognition that tourism development (like all economic regeneration) is competitive and challenging. Hamilton is a medium-sized city with an aging infrastructure located between two major tourism destinations, Toronto and Niagara Falls. It would therefore benefit from regional tourism but with trips becoming shorter and more intense this might be a long-term strategy for advocacy. Furthermore, as Selby noted for Liverpool, despite infrastructure changes a negative image can stay with a place despite rebranding efforts [19]. Branding is seen as a vital component of transforming industrial cities into knowledge-based, environmentally-friendly urban settings [29]. Hamilton's attempt to rebrand itself as the sustainable city or the bay city have met with limited success as to 
many it remains Steeltown or 'The Hammer' reflecting its blue-collared, hardedged past. Its skyline of steel plants and dilapidated downtown also conspire against its rebranding.

Hamilton's struggle to become a tourism destination is also not helped by its economic and political context. Important funding streams that could impact on services for visitors and the quality of destinations derive from the province with its many priorities and places requiring special assistance. Politically Hamilton's municipal council is often seen as a place of narrow, sectional, ward-based interests with the needs of the city often at odds with those of its incorporated suburbs. While a spirit of cooperation is often seen around such issues as poverty, homelessness, transportation, downtown revitalisation and airport development, the mechanisms to achieve these aims and the allocation of resources leading to winners and losers in the city are hotly contested. It often appears then that there is not a strategic plan to ensure economic regeneration. And if there is, actions are seldom sustained, being replaced by another way forward. Tourism development, although minor, is caught up in this political process.

But the plans do have many good ideas within them. As is suggested by many community economic development experts, using existing resources differently is an important strategy especially to keep local citizens engaged [30]. This suggests a cluster strategy So local strengths can be enhanced and built upon. Furthermore, the race to the bottom with tax incentives must be avoided and development will not occur if it ignores local context or is at an inappropriate scale or without a sufficiently detailed strategic and business plan. As Rogerson [6] notes, policy-makers must be realistic as to the tourism option and ensure it is linked to social and environmental priorities as well as economic ones. Tourism portfolios must be developed and a sound physical and network infrastructure be in place. Effective implementation requires good governance and cooperation. But talking the talk is much, much easier than walking the walk - and staying the course for sustainable tourism as part of economic regeneration.

\section{References}

[1] City of Hamilton, City of Hamilton: population, household and employment projection scenarios, Report to Council, Planning and Development Department, City of Hamilton, 2002.

[2] Lord, G.F. \& Price, A.C., Growth ideology in a period of decline, Social Problems 39, pp. 155-169, 1992.

[3] Roche, M., Mega-events and micro-modernization, British Journal of Sociology 43, 563-600, 1992.

[4] Mansfeld, Y., 'Industrial landscapes' as positive settings for tourism development in declining industrial cities, GeoJournal 28, pp. 457-463, 1992.

[5] Roberts, S.M. \& Schein, R.H., The entrepreneurial city, Professional Geographer 45, pp. 21-32, 1993. 
[6] Rogerson, C., Tourism-led local economic development, Urban Forum 13, pp. 95-119, 2002.

[7] Chiesura, A., The role of urban parks for the sustainable city, Landscape and Urban Planning 68, pp. 129-138, 2004.

[8] Davidson, R. \& Maitland, R., Tourism destinations, London: Hodder and Stoughton, 1997.

[9] Helmsing, A.H.J., Externalities, learning and governance, Development and Change 32, pp. 277-308, 2001.

[10] Briassoulis, H., Sustainable tourism and the question of the commons, Annals of Tourism Research 29, pp. 1065-85, 2002.

[11] Bradshaw, T.K. \& Blakely, E.J., What are 'third-wave' state economic development efforts? Economic Development Quarterly 13, pp. 229-44, 1999.

[12] Zremski, J., Down-and-out upstate, City Journal Autumn, http://www.cityjournal.org/printable.php?id=463, 1999.

[13] Law, C.M., Urban tourism and its contribution to economic regeneration, Urban Studies 29, pp. 29, 599-618, 1992.

[14] Jansen-Verbeke, M., Leisure, recreation and tourism in inner cities, Netherlands Geographical Studies 58, Amsterdam, 1988.

[15] Noll, R.G. \& Zimbalist, A. (eds), Sports, jobs and taxes, Washington: Brookings Institution Press, 1997.

[16] Marcouiller, D.W., Goodman, E., Fox, S. \& Scheler, D., Travel and tourism employment in Wisconsin, Madison: University of Wisconsin, Department of Urban and Regional Planning, 2004.

[17] Murray, G. (2007) 'Irritable Bilbao syndrome' spawns civic horrors, The Star, http://www.thestar.com/printArticle/168577, January 7, 2007.

[18] Gould, W. (2001) Spanish lessons for Milwaukee, Milwaukee Journal Sentinel, http://www2.jsonline.com/news/metro/may01/bilbao06050 501a.asp, May 5, 2001.

[19] Selby, M., Understanding Urban Tourism, London: IB Tauris, 2004.

[20] Xie, P.F., Developing industrial heritage tourism, Tourism Management 27, pp. 1321-30, 2006.

[21] Centre for Spatial Economics, City of Hamilton: population, household and employment projections, Hamilton: CSE, 2002.

[22] Bekkering, M. \& Eyles, J., Making a region sustainable, in M. Hoff (ed) Sustainable community development, Boca Raton: Lewis, pp 139-62, 1998.

[23] City of Hamilton, GRIDS - planning for smart growth over the next thirty years, Hamilton, http://www.myhamilton.ca/myhamilton/cityand government/citydepartments/planningecdev/longrangeplanning/growthrelat edintegrateddevelopmentstrategy/index, 2007.

[24] City of Hamilton, Economic development strategy: Hamilton clusters of innovation, City of Hamilton: Hamilton, 2005.

[25] City of Hamilton, Economic development review, City of Hamilton, Hamilton, http://www.investinhamilton.ca/publications/EcRev07.pdf, 2007.

[26] City of Hamilton, Tourism Hamilton marketing plan, Hamilton: City of Hamilton, 2008. 
[27] Tourism Hamilton, Annual report, Hamilton: City of Hamilton, 2007.

[28] Arnold, S., NHL and a tax deal too? Hamilton Spectator, http://www.thespec.com/article/202794, June 1, 2007.

[29] Jensen, O.B., Branding the contemporary city: urban branding as a regional growth agenda? Paper presented at Regional Studies Association conference, Aalborg, Denmark, 2005.

[30] Shaffer, R., Deller, S. \& Marcouiller, D.W. Rethinking community economic development, Economic Development Quarterly 20, pp. 59-74, 2006. 